\title{
Improving outcomes after autologous transplantation in relapsed/refractory Hodgkin lymphoma: a European expert perspective
}

\author{
Anna Sureda ${ }^{1,2^{*}}$, Marc André ${ }^{3}$, Peter Borchmann ${ }^{4}$, Maria G. da Silva ${ }^{5}$, Christian Gisselbrecht ${ }^{6}$, \\ Theodoros P. Vassilakopoulos ${ }^{7}$, Pier Luigi Zinzani ${ }^{8,9}$ and Jan Walewski ${ }^{10}$
}

\begin{abstract}
Autologous stem cell transplantation (ASCT) is a well-established approach to treatment of patients with relapsed/refractory $(\mathrm{R} / \mathrm{R})$ Hodgkin lymphoma $(\mathrm{HL})$ recommended by both the European Society for Medical Oncology and the National Comprehensive Cancer Network based on the results from randomized controlled studies. However, a considerable number of patients who receive ASCT will progress/relapse and display suboptimal post-transplant outcomes. Over recent years, a number of different strategies have been assessed to improve post-ASCT outcomes and augment $\mathrm{HL}$ cure rates. These include use of pre- and post-ASCT salvage therapies and post-ASCT consolidative therapy, with the greatest benefits demonstrated by targeted therapies, such as brentuximab vedotin. However, adoption of these new approaches has been inconsistent across different centers and regions.

In this article, we provide a European perspective on the available treatment options and likely future developments in the salvage and consolidation settings, with the aim to improve management of patients with $\mathrm{HL}$ who have a high risk of post-ASCT failure.
\end{abstract}

Conclusions: We conclude that early intervention with post-ASCT consolidation improves outcomes in patients with $\mathrm{R} / \mathrm{R} \mathrm{HL}$ who require ASCT. Future approvals of targeted agents are expected to further improve outcomes and provide additional treatment options in the coming age of personalized medicine.

Keywords: Consolidation, HL, Salvage, Stem cell transplantation

\section{Background}

Hodgkin lymphoma $(\mathrm{HL})$ is considered to be a curable hematological malignancy. The currently available chemotherapies and targeted therapies deliver frontline cure rates of approximately $90 \%$ for patients with early- or intermediatestage disease and $70-90 \%$ for patients with advanced-stage disease [1-7]. For patients who either relapse or are refractory

\footnotetext{
*Correspondence: asureda@iconcologia.net

${ }^{1}$ Hematology Department, Hematopoietic Stem Cell Transplant Programme, Institut Català d'Oncologia-Hospital Duran i Reynals, Gran Via de l'Hospitalet, 199 - 203, 08908 Barcelona, Spain

${ }^{2}$ Institut d'Investigació Biomèdica de Bellvitge (IDIBELL), Universitat de Barcelona (UB), Barcelona, Spain

Full list of author information is available at the end of the article
}

to frontline treatment, the standard of care comprises salvage chemotherapy followed by autologous stem cell transplantation (ASCT) [8-11]. Despite this intensified approach, up to $50 \%$ of patients will experience progressive disease following ASCT $[9,12,13]$, representing a population with high-risk disease. This led to initiation of clinical studies in the 1990s to improve post-ASCT outcomes and consequently improve HL cure rates [14, 15], many of which showed less than satisfactory results, until the introduction of post-ASCT consolidation with brentuximab vedotin, an anti-cluster of differentiation 30 (CD30) antibody-drug conjugate (ADC). Brentuximab vedotin is able to improve progression-free survival (PFS) in patients with relapsed/refractory (R/R) classical

(c) The Author(s). 2020 Open Access This article is licensed under a Creative Commons Attribution 4.0 International License, which permits use, sharing, adaptation, distribution and reproduction in any medium or format, as long as you give appropriate credit to the original author(s) and the source, provide a link to the Creative Commons licence, and indicate if changes were made. The images or other third party material in this article are included in the article's Creative Commons licence, unless indicated otherwise in a credit line to the material. If material is not included in the article's Creative Commons licence and your intended use is not permitted by statutory regulation or exceeds the permitted use, you will need to obtain permission directly from the copyright holder. To view a copy of this licence, visit http://creativecommons.org/licenses/by/4.0/. The Creative Commons Public Domain Dedication waiver (http://creativecommons.org/publicdomain/zero/1.0/) applies to the data made available in this article, unless otherwise stated in a credit line to the data. 
HL (cHL) and a high risk of relapse post-ASCT $[16,17]$, and following its regulatory approval in the R/R cHL consolidation setting, a new generation of targeted therapies are being developed for use in this high-risk population.

This article will provide a European perspective on the optimal treatment of patients with high-risk R/R HL in the peri-ASCT setting, based on the current data from clinical studies and real-world evidence, with a focus on use of targeted agents to improve post-ASCT outcomes.

\section{Historical perspective on the role of ASCT in R/R HL}

Two randomized studies provide the basis for the use of high-dose chemotherapy (HDC) plus ASCT as a standard of care in patients with R/R HL. The British National Lymphoma Investigation compared the activity of a combination of carmustine, etoposide, cytarabine, and melphalan (BEAM) plus autologous bone marrow transplant (ABMT) versus up to 3 cycles of mini-BEAM (lower doses of the BEAM drug combination) without ABMT in patients with R/R HL [18]. Although the study failed to show a significant difference in overall survival (OS) between arms, there were significant differences in favor of BEAM + ABMT in event-free survival (EFS; $p=0.025)$ and PFS $(p=0.005)$.

The BEAM-ASCT regimen was also assessed by the German Hodgkin Study Group (GHSG) and the Lymphoma Working Party of the European Group for Blood and Marrow Transplantation (EBMT) versus dexamethasone plus BEAM (Dexa-BEAM) [9]. After 3 years' follow-up, there was no significant difference in OS between treatment groups; however, freedom from treatment failure (FFTF) was significantly improved in the BEAM-ASCT group compared with the Dexa-BEAM group (55\% vs 34\%; $p=0.019$ ).

Despite the non-significant survival benefit with BEAM + ABMT/ASCT, this strategy was established as the historical standard of care based on the clear benefits on tumor control over conventional-dose salvage therapy alone. The lack of a demonstrable OS benefit of HDC + ASCT when compared with conventional chemotherapy in these clinical studies may be attributed to the small number of patients in the studies. A later detailed meta-analysis of data from the two studies suggested a trend towards an OS advantage for patients receiving HDC + ASCT compared with conventional chemotherapy alone (hazard ratio [HR] 0.67, $p=$ 0.10) [19]. In addition, the use of ASCT later in the course of the disease may have confounded detection of any potential effects of HDC + ASCT on OS.

\section{Improving post-ASCT outcomes in HL: pre-transplant strategies}

\section{Current conventional salvage chemotherapy}

The most widely investigated strategy to improve postASCT outcomes is the optimization of pre-ASCT salvage chemotherapy. A variety of regimens have been studied, including platinum-based dexamethasone, cytarabine, and cisplatin/doxorubicin, methylprednisolone, high-dose cytarabine, and cisplatin/etoposide, methylprednisolone, high-dose cytarabine, and cisplatin (DHAP/ASHAP/ ESHAP [20-24]), ifosfamide-based (MINE/ICE/IVE/IVOx [25-29]), and gemcitabine-based combinations (GVD/ IGEV/GDP/GemOx/BeGEV) [30-34]. Most of these studies evaluated the efficacy of salvage chemotherapy in terms of objective responses and the impact on OS and posttransplant PFS; reports of the impact on stem cell mobilization, stem cell quality, and stem cell transplantation (SCT) rates are inconsistent (Table 1). Objective response rates (ORRs) ranged from 61\% with GVD (in ASCT-naive patients) to $88 / 89 \%$ with ICE and DHAP [20, $26,27]$, and complete response (CR) rate was as low as $17 \%$ with GDP and as high as $73 \%$ with BeGEV [32, 34]. PFS was $78 \%$ with ESHAP in patients who achieved CR, but $16 \%$ in those who achieved partial remission (PR) [24]; ICE treatment resulted in a PFS of 70\% [35], but only 53 and $62 \%$ with IGEV and BeGEV, respectively [31, 34]. EFS was $36 \%$ with ASHAP and $68 \%$ with ICE $[22,26]$. OS with ESHAP was estimated at $35 \%$ at 3 years in one study and $73 \%$ at 5 years in another study [23, 24]. However, the absence of prospective randomized studies comparing the regimens makes it impossible to reach conclusions regarding the superiority of particular combinations. This is reflected in the current European Society for Medical Oncology (ESMO) and National Comprehensive Cancer Network (NCCN) treatment guidelines, which do not recommend any specific salvage therapy regimen for patients with $\mathrm{R} / \mathrm{R}$ HL $[10,11,36]$. Instead, appropriate therapy is generally selected based on patient-related factors, familiarity of the treatment center with particular regimens, treatment as in-patients versus out-patients, and the toxicity profile of each salvage regimen - patients with concomitant coronary, pulmonary, or renal diseases may require different salvage management.

Patients who achieve a response, particularly a CR, with conventional salvage chemotherapy prior to ASCT, are likely to have an improved clinical outcome compared with patients who have partially or totally chemo-resistant disease at relapse. Moskowitz et al. reported an analysis of long-term outcomes in 75 patients demonstrating significant improvements $(p<0.001)$ in EFS (60\% vs $19 \%)$, PFS (62\% vs $23 \%)$, and OS (66\% vs $17 \%)$ in patients who responded to standard-dose second-line therapy after relapse, compared with those who had a poor response, respectively [37]. Similarly, in a prospective analysis of 195 patients treated over a 20 -year period, patients who had achieved a CR with conventional salvage chemotherapy and who were still in CR at the time of ASCT had a 5-year OS of 79\%, which dropped to $59 \%$ for those in PR, and 17\% for those with resistant disease $(p<0.0001)$. Corresponding 5 -year PFS rates 
Table 1 Conventional chemotherapy-based salvage regimens assessed in patients with $R / R H L$

\begin{tabular}{|c|c|c|c|c|}
\hline \multirow{2}{*}{$\begin{array}{l}\text { Regimen(s) } \\
\text { MINE [25] }\end{array}$} & \multirow{2}{*}{$\begin{array}{l}\text { Patients, } N \\
100\end{array}$} & \multirow{2}{*}{$\begin{array}{l}\text { Pre-ASCT response rate } \\
\mathrm{ORR}=75 \%\end{array}$} & \multicolumn{2}{|c|}{ Survival data in overall patient group ( \pm ASCT) } \\
\hline & & & 2-year survival rate & $59 \%$ \\
\hline \multirow[t]{2}{*}{ ASHAP [22] } & \multirow[t]{2}{*}{56} & \multirow{2}{*}{$\begin{array}{l}\mathrm{ORR}=70 \%(\mathrm{CR}=34 \% \\
\mathrm{PR}=36 \%)\end{array}$} & OS, 5-year follow-up & $41 \%$ \\
\hline & & & EFS, 5-year follow-up & $36 \%$ \\
\hline DHAP [20] & 102 & $\begin{array}{l}\mathrm{ORR}=88 \% \\
(\mathrm{CR}=21 \%, \mathrm{PR}=67 \%)\end{array}$ & NR & NR \\
\hline \multirow[t]{2}{*}{ ESHAP [23] } & \multirow[t]{2}{*}{22} & \multirow[t]{2}{*}{$\mathrm{ORR}=73 \%$} & 50-month follow-up & $32 \%$ alive and disease-free \\
\hline & & & 3-year estimates & $\begin{array}{l}\text { OS }=35 \% \\
\text { Disease-free }=27 \%\end{array}$ \\
\hline \multirow[t]{2}{*}{ ESHAP [24] } & \multirow[t]{2}{*}{82} & \multirow{2}{*}{$\begin{array}{l}\mathrm{ORR}=67 \% \\
(\mathrm{CR}=50 \%)\end{array}$} & OS, 5-year follow-up & $72.6 \%$ \\
\hline & & & PFS, 5-year follow-up & $\begin{array}{l}\text { - Pts achieving } C R=78 \% \\
\text { - Pts achieving } P R=16 \% \\
p<0.01)\end{array}$ \\
\hline \multirow[t]{2}{*}{ ICE [26] } & \multirow[t]{2}{*}{65} & \multirow{2}{*}{$\begin{array}{l}\mathrm{ORR}=88 \% \\
(\mathrm{CR}=26 \%, \mathrm{PR}=58 \%)\end{array}$} & OS, 43-month follow-up & $83 \%$ \\
\hline & & & EFS, 43-month follow-up & $68 \%$ \\
\hline \multirow[t]{2}{*}{ ICE [27] } & \multirow{2}{*}{$\begin{array}{l}\mathrm{R} / \mathrm{R} \mathrm{HL}(n=13) \\
\text { non-HL }(n=62)\end{array}$} & \multirow{2}{*}{$\begin{array}{l}\mathrm{ORR}=89 \% \\
(\mathrm{CR}=29 \%, \mathrm{PR}=60 \%)\end{array}$} & OS, 24-month follow-up & $65 \%$ (all pts) \\
\hline & & & EFS, 24-month follow-up & $42 \%$ (all pts) \\
\hline \multirow[t]{2}{*}{ ICE/alCE [35] } & \multirow[t]{2}{*}{97} & \multirow[t]{2}{*}{ NR } & OS, 51-month follow-up & $80 \%$ \\
\hline & & & PFS, 51-month follow-up & $70 \%$ \\
\hline IVE [28] & 51 & $\begin{array}{l}\text { ORR }=84 \% \\
(C R=60 \% \text {, good } P R=8 \% \\
P R=16 \%)\end{array}$ & NR & NR \\
\hline \multirow[t]{2}{*}{ IVOx [29] } & \multirow[t]{2}{*}{34} & \multirow[t]{2}{*}{$\mathrm{ORR}=76 \%(C R=32 \%)$} & OS, 5-year follow-up & $74 \%$ \\
\hline & & & EFS, 5-year follow-up & $63 \%$ \\
\hline \multirow[t]{2}{*}{ GVD pre- or post-ASCT [30] } & \multirow[t]{2}{*}{94} & \multirow[t]{2}{*}{$\begin{array}{l}\text { ASCT-naïve pts. ORR }=61 \% \\
\text { Prior-SCT pts. ORR }=75 \%\end{array}$} & OS, 3.6-year follow-up & $\begin{array}{l}\text { - SCT-naïve pts. median ORR =61\% } \\
\text { - Prior-SCT pts. ORR }=75 \%\end{array}$ \\
\hline & & & EFS, 3.6-year follow-up & $\begin{array}{l}\text { - SCT-naïve pts. median EFS not reached, } \\
52 \% \text { progression-free at } 4 \text { years } \\
\text { • Prior-SCT pts. median EFS duration } 8.5 \text { months }\end{array}$ \\
\hline \multirow[t]{2}{*}{ IGEV [31] } & \multirow[t]{2}{*}{91} & \multirow[t]{2}{*}{$C R=53.8 \%, P R=27.5 \%$} & OS, 3-year follow-up & $70.03 \%$ \\
\hline & & & PFS, 3-year follow-up & $52.98 \%$ \\
\hline \multirow[t]{2}{*}{ BeGEV [34] } & \multirow[t]{2}{*}{59} & $\mathrm{ORR}=83 \%$ & OS, 2-year follow-up & $77.6 \%$ \\
\hline & & & PFS, 2-year follow-up & $62.2 \%$ \\
\hline GDP [32] & 23 & $\begin{array}{l}\mathrm{ORR}=69.5 \% \\
(\mathrm{CR}=17.3 \%, \mathrm{PR}=52.2 \%)\end{array}$ & NR & NR \\
\hline GemOx [33] & 24 & $\mathrm{ORR}=71 \%$ & OS, 3-year follow-up & Median of 26 months \\
\hline & & $(C R=38 \%, P R=33 \%)$ & PFS, 3-year follow-up & Median of 14 months \\
\hline
\end{tabular}

NR not reported, Pts patients

were $69 \%$ versus $44 \%$ versus $14 \%(p<0.0001)$ [38]. More recently, in a phase II study of 97 patients, those who proceeded to SCT with a positronemission tomography (PET)-negative status achieved an EFS of $>80 \%$, compared with $29 \%$ in PET-positive patients [35]. Collectively, these studies demonstrate that the aim of any modern salvage therapy is to produce a deep remission and PET-negative status prior to undergoing HDC-ASCT. However, ASCT should not be solely withheld due to lack of PETnegativity [39].
Can salvage therapy be further improved with conventional cytotoxic agents?

The GHSG have investigated the concept of escalated pre-ASCT chemotherapy, delivered as sequential-HDC, compared with standard HDC, in an effort to improve treatment outcomes for patients with $\mathrm{R} / \mathrm{R}$ HL receiving HDC + ASCT [40]. In the GHSG study of standard versus intensified BEAM-ASCT following DHAP in patients with relapsed HL $(n=241)$, there were no significant differences in FFTF $(p=0.56)$ or OS $(0.82)$ between the study arms. Toxicity was considerably higher in the 
intensified arm, with increased rates of grade $3 / 4$ adverse events (AEs), although this did not translate into increased mortality.

Patients who achieve a CR following induction chemotherapy are highly likely to respond to post-relapse interventions [31]. Previous studies in patients with HL who have experienced multiple relapses have demonstrated that bendamustine monotherapy has promising activity, with patients who were ineligible for ASCT, or for whom ASCT had failed, achieving CR rates of $25-35 \%$ [41-43]. In an open-label phase II study, ORR was $83 \%$ ( $\mathrm{CR}=73 \%$ ) following 4 cycles of BeGEV as induction therapy before ASCT in 43/49 patients. Two-year PFS and OS rates in the overall patient population were 62.2 and $77.6 \%$, respectively, and 80.8 and $89.3 \%$ among patients who underwent ASCT [34].

\section{Optimization of salvage therapy with the use of brentuximab vedotin}

Brentuximab vedotin is currently approved as a monotherapy for adult patients with R/R CD30-positive cHL following ASCT or following $\geq 2$ prior therapies when ASCT or multi-agent chemotherapy is not a treatment option [44]. The pivotal phase II SG035-0003 study of brentuximab vedotin $(1.8 \mathrm{mg} / \mathrm{kg}$ every 3 weeks [Q3W]) after failed ASCT in 102 patients with R/R HL, reported median OS of 22.4 months and median PFS of 5.6 months at the primary analysis [45]. With prolonged follow-up (median 35.1 months) estimated 5-year OS and PFS rates were 41 and 22\%, respectively [46]. Corresponding OS and PFS rates amongst the $33 \%$ of patients who achieved a CR were 64 and $52 \%$, and the median response duration was not reached. The prospective phase IV C25007 study evaluated brentuximab vedotin (1.8 $\mathrm{mg} / \mathrm{kg} \mathrm{Q} 3 W)$ in $60 \mathrm{R} / \mathrm{R}$ HL patients who were unsuitable for ASCT or multi-agent chemotherapy [47]. The ORR was $50 \%(C R=12 \%), 47 \%$ of patients were bridged to ASCT, and the estimated 12-month OS was $86 \%$, thus enabling patients with high-risk disease to receive ASCT, even if they had a suboptimal response to frontline treatment or chemotherapy/radiotherapy-based salvage.

Lately, brentuximab vedotin has been assessed alone and in combination with conventional chemotherapybased regimens for salvage therapy prior to ASCT in several studies (Table 2). A phase II study assessed 4 cycles of standard-dose, single-agent brentuximab vedotin $(1.8 \mathrm{mg} / \mathrm{kg} \mathrm{Q} 3 \mathrm{~W})$ as salvage treatment following induction therapy with doxorubicin, bleomycin, vinblastine, and dacarbazine (ABVD) and/or bleomycin, etoposide, doxorubicin, cyclophosphamide, vincristine, procarbazine, and prednisone (BEACOPP) [52]. In 37 patients, ORR was $69 \%$ and CR rate was $35 \%$; $89 \%$ of patients were able to proceed to ASCT, either with or without additional chemotherapy.
Encouraging results with PET-adapted salvage therapy have been reported by Moskowitz et al. [16] in a phase II open-label study to assess the efficacy of 2 cycles of brentuximab vedotin-based salvage $(1.2 \mathrm{mg} / \mathrm{kg}$ on days 1,8 , and 15 ) in patients with R/R HL who had failed one previous doxorubicin-containing regimen. Following the first 2 cycles of brentuximab vedotin, $27 \%$ of patients were PET-negative and proceeded directly to ASCT and $69 \%$ initiated augmented ifosfamide, carboplatin, and etoposide (aICE) [16]. Seventy-six percent of patients achieved PET-negativity prior to HDC/ASCT, thus maximizing the potential for improved post-ASCT outcomes. Patients treated with 3 cycles of brentuximab vedotin also achieved similar rates of PET-negativity (30\%) and proceeded directly to ASCT, whilst the remainder received either aICE or ICE [39]. Prior to transplant, $80 \%$ of patients had achieved PET-negativity with either brentuximab vedotin alone or combined with aICE/ICE, and with 2 years' follow-up EFS was $82 \%$.

Brentuximab vedotin combined with standard ICE has also shown promise in phase I/II clinical studies [50, 51]. In the NCT02227199 study, 20/23 evaluable patients previously treated with ABVD achieved a PET CR per investigator review following brentuximab vedotin + ICE; 70\% were in PET CR per independent central review [50]. Final data from the Lymphoma Academic Research Organisation phase I/II study showed that $69 \%(n=27 / 39)$ of patients who received brentuximab vedotin $(1.8 \mathrm{mg} / \mathrm{kg})$ plus ICE achieved a complete metabolic response (CMR) and $26 \%$ achieved a partial metabolic response. Twenty patients in CMR went on to receive ASCT [51]. Neither study reported any unexpected toxicities.

Two brentuximab vedotin + platinum-based chemotherapy combinations appear particularly promising: brentuximab vedotin + DHAP (B + DHAP), and brentuximab vedotin + ESHAP (BrESHAP). In the phase II BRaVE study, the high metabolic CR rate of $79 \%$ achieved with $B+$ DHAP suggests that this approach is worth investigating further [48]. Moreover, the Grupo Español de Linfomas y Trasplantes de Médula Ósea (GELTAMO) study further demonstrated the potential for brentuximab vedotin combinations with chemotherapy in the pre-ASCT setting. After approximately 27 months of follow-up, $74 \%$ of patients were FFTF, PFS was $71 \%$, and OS was $91 \%$ [49].

The combination of brentuximab vedotin $(1.8 \mathrm{mg} / \mathrm{kg}$ Q3W) and bendamustine $\left(90 \mathrm{mg} / \mathrm{m}^{2}\right.$ days $\left.1-2 \mathrm{Q} 3 \mathrm{~W}\right)$ was highly active as first salvage therapy for patients with R/R HL in a phase I/II study involving 55 patients [53]. ORR was 93\% and CR was $74 \%$ after a median of 2 cycles of therapy.

Interim results of another phase I/II study have also demonstrated the utility of 4 cycles of a brentuximab vedotin $(1.8 \mathrm{mg} / \mathrm{kg}$ Q3W) combined with nivolumab (3.0 mg/kg Q3W) combination as initial salvage therapy 
Table 2 Brentuximab vedotin-based salvage regimens assessed in patients with R/R HL

\begin{tabular}{|c|c|c|c|c|}
\hline Regimen(s) & Patients & Response before transplant & os & PFS \\
\hline $\mathrm{B}+\mathrm{DHAP}[48]$ & $\mathrm{R} / \mathrm{R} \mathrm{HL}(\mathrm{N}=61)$ & $\begin{array}{l}\text { - Metabolic CR 79\% } \\
\text { - Metabolic PR 8\% } \\
\text { - Progressive disease } 7 \% \\
\text { - } 87 \% \text { of pts. were mobilized and received } \\
\text { ASCT }\end{array}$ & $\begin{array}{l}\text { 2-year } \\
\text { OS 92\% }\end{array}$ & 2-year PFS 76\% \\
\hline BrESHAP [49] & $\begin{array}{l}\mathrm{R} / \mathrm{R} \mathrm{HL} \text { after frontline chemotherapy } \\
(N=66)\end{array}$ & $\begin{array}{l}\text { - ORR } 91 \% \\
\text { - CR } 82 \% \\
\text { - PR 10\% } \\
\text { - } 64 \text { pts. were mobilized and } 60 \text { received SCT }\end{array}$ & $\begin{array}{l}\text { 30-month } \\
\text { OS } 91 \%\end{array}$ & 30-month PFS 71\% \\
\hline $\begin{array}{l}\text { PET-adapted brentuximab } \\
\text { vedotin }+ \text { alCE [16] }\end{array}$ & $\begin{array}{l}\mathrm{R} / \mathrm{R} H \mathrm{HL} \text { who had failed one previous } \\
\text { doxorubicin regimen }(N=46)\end{array}$ & $\begin{array}{l}\text { - } 30 \% \text { of pts. achieved PET-negativity with } \\
\text { brentuximab vedotin alone } \\
\text { - alCE increased PET-negativity rates to } 80 \%\end{array}$ & $N R$ & 2-year EFS $=82 \%$ \\
\hline $\begin{array}{l}\text { PET-adapted brentuximab } \\
\text { vedotin }+ \text { alCE }[50,51]\end{array}$ & $\begin{array}{l}\text { First relapse or primary refractory } \\
\text { CD30+ CHL } \\
(N=24[50]) \\
(N=42[51])\end{array}$ & $\begin{array}{l}\text { - } 87 \% \text { CR per investigator, } 70 \% \text { per } \\
\text { independent review [50] } \\
\text { - } 69.2 \% \text { CMR [51] }\end{array}$ & NR & $\begin{array}{l}\text { 1-year PFS estimate } \\
69 \%(95 \% \mathrm{Cl} 53-81 \%)\end{array}$ \\
\hline Brentuximab vedotin [52] & $\mathrm{R} / \mathrm{R} \mathrm{HL}(\mathrm{N}=37)$ & $\begin{array}{l}\text { - Best ORR }=69 \%(C R=33 \%) \\
\text { - } 12 \text { pts. with CR received SCT } \\
\text { - } 11 / 13 \text { pts. with PR and all pts. with SD/PR } \\
\text { required additional chemotherapy }\end{array}$ & $N R$ & NR \\
\hline $\begin{array}{l}\text { Brentuximab vedotin } \\
+ \text { bendamustine }[53]\end{array}$ & $\mathrm{R} / \mathrm{R} \mathrm{HL}(\mathrm{N}=55)$ & $\begin{array}{l}\text { - ORR } 92.5 \% \\
\text { - CR } 73.6 \% \\
\text { - } 41 \text { patients were mobilized and } 40 \\
\text { underwent ASCT }\end{array}$ & NR & 2-year PFS 62.6\% \\
\hline $\begin{array}{l}\text { Brentuximab vedotin } \\
+ \text { nivolumab }[54]\end{array}$ & $\mathrm{R} / \mathrm{R} \mathrm{HL}(\mathrm{N}=61)$ & $\begin{array}{l}\text { - ORR } 82 \% \\
\text { - CR } 61 \% \\
\text {. } 54 \text { pts. underwent ASCT }\end{array}$ & $N R$ & $\begin{array}{l}\text { 6-month estimated } \\
\text { PFS } 89 \%\end{array}$ \\
\hline
\end{tabular}

for patients with $\mathrm{R} / \mathrm{R} \mathrm{HL}$ [54]. ORR in all treated patients $(n=61)$ was $82 \%$, and CR was $61 \%$.

In summary, single-agent brentuximab vedotin as a salvage therapy shows activity that is not that different to that seen with classical chemotherapy regimens, albeit with a lower systemic toxicity, although these have not been compared in a prospective, randomized phase III study. Clinical studies of brentuximab vedotin combined with chemotherapy build on the demonstrated efficacy of brentuximab vedotin monotherapy, with high CR rates observed with combination therapy, and with no new safety signals. Again, these observations need to be confirmed in prospective, randomized phase III studies, such as the BRESELIBET study (NCT04378647) that was opened to enrolment in June 2020. Despite the low patient numbers in these studies, brentuximab vedotin plus chemotherapy regimens are frequently used as salvage therapy in the clinic.

\section{Tandem SCT as a strategy to improve ASCT outcomes}

The successful implementation of aggressive tandem transplant programs in myeloma led the Lymphoma Study Association (LYSA) and the Société Francaise de Greffe de Moelle (SFGM) to conduct an exploratory joint phase II study to assess the feasibility of tandem ASCT in patients with high-risk HL, defined as primary refractory disease or $\geq 2$ of the following risk factors at first relapse: time to relapse $<12$ months, stage III/IV at relapse, and relapse within previously irradiated sites [55]. In the high-risk group, 5-year freedom from second failure rate was $46 \%$, which was higher than the $30 \%$ reported by historical studies, and OS rate was $57 \%$. After a median follow-up of 10.3 years, respective failure-free survival and OS rates were 64 and $70 \%$ for intermediaterisk patients and 41 and $47 \%$ for high-risk patients [56].

In 2018, the Southwest Oncology Group published results from a phase II study to assess the efficacy of tandem ASCT for 98 patients with primary progressive or recurrent HL [57]. After a median of 6.2 years' followup, 2-year and 5-year PFS rates were 63 and 55\%, and 2year and 5-year OS rates were 91 and 84\%, respectively.

Tandem SCT utilizing ASCT followed by an allogeneic SCT (allo-SCT) was assessed by the LYSA in a multicenter observational study of 120 patients with high-risk R/R HL who were prospectively registered on a French national database [58]. After 43 months' median follow-up the 2year PFS and OS rates were 71 and $85 \%$, respectively, in tandem-transplanted patients, but with no significant difference between ASCT-allo-SCT or tandem ASCT options.

A retrospective analysis of patients with $\mathrm{R} / \mathrm{R}$ HL who received tandem SCT between January 2004 and December 2015, performed by the Lymphoma Working Party of the EBMT, found that dual SCT might be effective in high-risk populations [59]. Three years after dual SCT, 
PFS was $53 \%$, OS was $72,34 \%$ of patients had relapsed, and $13 \%$ had non-relapse mortality.

These clinical studies suggest that there may be a place for tandem SCT in the treatment of R/R HL, although the exact patient subgroup that will derive the most benefit from this strategy remains to be defined. These strategies may become less relevant in the era of novel agents. Integration of pre-ASCT PET-response assessment, post-ASCT salvage and consolidation therapies, including targeted agents, may offer higher survival rates with less intensive regimens.

\section{Improving post-ASCT outcomes in HL: post-transplant strategies}

Despite efforts to optimize pre-ASCT strategies, many patients will still relapse after receiving ASCT [60]. Use of post-ASCT consolidation, even when there is no detectable residual lymphoma, can prevent or delay relapse or progression. Prospective and retrospective studies have demonstrated improved PFS in patients who received post-ASCT rituximab maintenance compared with no maintenance in patients with follicular lymphoma [61, 62]. These studies suggest that maintenance therapy plays a role in suppressing emergence of minimal residual disease (MRD) leading to relapse. A randomized study by Le Gouill et al., demonstrated clearance of MRD and improved PFS and OS in patients with mantle cell lymphoma (MCL) treated with post-ASCT rituximab consolidation for 3 years [63]. The current HL treatment guidelines fail to emphasize the importance of the timing of such medical intervention. As relapse/progression tends to occur soon after ASCT, the greatest therapeutic effect is likely to be achieved with a consolidation treatment delivered as early as possible after receipt of ASCT [64].

To ensure that patients are exposed to an effective consolidation regimen for as long as possible, it is important that consolidative therapies deliver a combination of efficacy and acceptable tolerability for patients. Novel targeted therapies that are either approved or are under investigation in this setting are discussed below and summarized in Table 3.

\section{Brentuximab vedotin as consolidation therapy}

Consolidation therapy is administered to patients who may have undetectable residual lymphoma and those who may already be cured. Therefore, the optimal consolidation therapy should have a favorable/low toxicity profile that does not impair hematopoietic and immunological recovery post-ASCT, with minimal impact on non-lymphoid/hematopoietic tissues. As biologic treatment options, such as brentuximab vedotin, are less toxic than traditional cytotoxic chemotherapy, they may be an ideal treatment option in this setting.
The utility of brentuximab vedotin as early consolidation therapy after ASCT in patients with high-risk HL was explored in the phase III AETHERA study (see Table 3) [65]. Patients enrolled in AETHERA $(n=329)$ had one of the following pre-ASCT risk factors for relapse: primary refractory HL (i.e., CR not achieved with frontline chemotherapy), relapsed HL with a duration of initial remission $<12$ months, or extranodal involvement at the start of preASCT HDC. After a median of 30 months' follow-up, PFS per independent review was significantly longer with brentuximab vedotin compared with placebo (median PFS of 42.9 vs 24.1 months [HR $0.57 ; 95 \%$ CI $0.40-0.81$ ]; $p=$ $0.0013)$ [65]. PFS benefit was consistent across pre-specified subgroups, including patients with primary refractory HL and those who relapsed $<12$ months after frontline therapy. After 5 years of follow-up, brentuximab vedotin continued to demonstrate sustained PFS benefit (HR 0.52; 95\% CI $0.38-0.72$ ), with 5-year per investigator PFS rates of 59\% versus $41 \%$ with placebo, implying that a considerable proportion of these patients might have been cured [17]. This long-term PFS benefit with brentuximab vedotin was more pronounced in patients with higher numbers of pre-ASCT risk factors, which included relapse within $<12$ months or refractoriness to frontline therapy, best response of PR or stable disease (SD) to most recent salvage therapy, extranodal disease at pre-ASCT relapse, B-symptoms at pretransplant relapse, or $\geq 2$ prior salvage therapies. An OS analysis has not yet been performed, as the planned number of events has not been reached. Brentuximab vedotin consolidation was well tolerated in the AETHERA study, with 93 of 167 patients (56\%) experiencing grade 3/4 AEs [65]. Sixty-seven percent of brentuximab vedotin-treated patients experienced some level of peripheral neuropathy, $90 \%$ of which had either completely resolved or decreased in severity after 5 years' follow-up [17].

The results of the AETHERA study are reflected in the HL treatment guidelines developed by ESMO and NCCN, and the lymphoma post-ASCT maintenance therapy guidelines developed by a joint expert panel consisting members of American Society for Blood and Marrow Transplantation (ASBMT), Center for International Blood and Marrow Transplant Research (CIBMTR), and EBMT [10, 11, 36]. ESMO guidelines recommend consolidation with brentuximab vedotin following HDC-ASCT in patients presenting with $\geq 1$ of the following risk factors: primary disease progression, early disease recurrence after the end of frontline treatment $(<12$ months), and extranodal disease at the time of relapse, without specifying the duration of consolidation therapy [11]. NCCN recommend brentuximab vedotin for 1 year for patients with a high risk of relapse, defined as $\geq 2$ of the following risk factors: remission lasting $<1$ year, extranodal involvement, PET-positive response at time of transplant, B symptoms, and/or $>1$ salvage/subsequent therapy regimen [10]. The ASBMT, CIBMTR, and 
Table 3 Novel targeted post-ASCT consolidative options in development or approved for use in R/R HL

\section{Targeted agent \\ ADCs \\ Brentuximab vedotin (anti- \\ CD30; monotherapy) \\ phase III AETHERA study \\ (NCT01 100502) [17, 65] \\ Camidanlumab tesirine (anti- \\ CD25; monotherapy) phase I \\ study (NCT00516217) [66] \\ Histone deacetylase inhibitors}

Panobinostat (monotherapy) phase III (NCT01034163) [67]

\section{Treatment setting}

Consolidation therapy after ASCT in patients with $\mathrm{HL}$ at high risk of progression or relapse $(n=165$ brentuximab vedotin arm)

$$
\begin{array}{ll}
\text { R/R HL (median } 5 \text { prior lines; } n=26) & \text { • ORR } 81 \% \\
& \text { - CR } 50 \%
\end{array}
$$

Consolidation therapy after HDC and ASCT in patients with $\mathrm{HL}$ at high risk of relapse ( $n=27$ panobinostat arm)
R/R CHL after ASCT and brentuximab ORR 69\% vedotin

monotherapy) phase

CheckMate 205 study

(NCT02181738) [68, 69]

Pembrolizumab (anti-PD-1; monotherapy)

(NCT02362997) [70]

Galiximab (anti-CD80) phase II CALGB 50602 study (NCT00516217) [71]

Lucatumumab (anti-CD40)

phase la/ll study

(NCT00670592) [72]

TNX-650 (anti-IL-13) phase I/II study (NCT00441818)

Relatlimib (anti-LAG-3) phase I/ R/R HL

II study with/without nivolumab (NCT02061761)

AMG655 (anti-TRAIL) with bortezomib or vorinostat phase lb study (NCT00791011)

RFT5-SPMT-dgA (anti-CD25)

Alemtuzumab (anti-CD52)

phase II study with dose-

adjusted-EPOCH regimen

(NCT01030900)

\section{Bispecific antibody}

AFM13 (anti-CD30/CD16a; monotherapy) phase I study complete; phase II ongoing (NCT02321592) [73]

AFM13 (anti-CD30/CD16a; plus pembrolizumab) phase $\mathrm{Ib}$ KEYNOTE-206 study (NCT02665650) [74]

\section{CAR-T cells}

Anti-CD30

RELY-30 phase I study

(NCT02917083) [75]
Post-ASCT consolidation therapy in achieved a CR or PR with salvage chemotherapy $(N=31)$

$\mathrm{R} / \mathrm{R} \mathrm{HL}$; median 3 prior regimens $(n=$ 29)

$\mathrm{R} / \mathrm{R} \mathrm{HL}(n=37)$

Refractory $\mathrm{HL}$

R/R Lymphoma

$\mathrm{R} / \mathrm{R} \mathrm{HL}$

$\mathrm{R} / \mathrm{R} \mathrm{HL}$

Heavily-pretreated R/R HL $(n=28)$

$\mathrm{R} / \mathrm{R} \mathrm{HL}$ (failed brentuximab vedotin; $n=30)$

$\mathrm{R} / \mathrm{R} \mathrm{HL}$

Median 5 prior therapies $(n=14)$ patients with $\mathrm{R} / \mathrm{R} \mathrm{CHL}$ who had

- OS rate at 18 months: $100 \%$
- 2-year PFS rate: $63 \%$

- 5-year PFS rate: 59\%

Study discontinued early due to poor accrual (41/367 planned patients enrolled), so efficacy not formally evaluated

\section{Safety}

- Grade 3/4 AEs: 16\%

- Peripheral neuropathy: $67 \%$ ( $90 \%$ of which had improved or completely resolved after 5 years' follow-up)

- Grade $\geq 3$ treatment-emergent adverse events: $62 \%$

- Grade 3/4 AEs: 65\%. Most frequent:

- Neutropenia (27\%)

- Thrombocytopenia (15\%)

- Diarrhea, vomiting, fatigue (12\%)

- Grade 3/4 AEs were low

- PFS rate at 18 months: $82 \%$

- Grade $\geq 2$ AEs: $80 \%$

- Grade $\geq 3$ AEs: $30 \%$

- Immune-related AEs: 43\%

- ORR $10.3 \%$

- Median PFS 1.6 months

- Minimal grade 3/4 toxicities

- ORR $13.5 \%$

- Grade 3/4 AEs: 65\% (HL and $\mathrm{NHL}$ )

- Study in progress

- Study in progress

- No longer in development

- No longer in development

- Study in progress (monotherapy failed)

- Grade $\geq 3$ AEs: $29 \%$

- ORR 88\%

- CR $46 \%$

- 6-month PFS 77\%

- Grade 3/4 AEs included infusion-related reactions in $13 \%$

- Not reported 
Table 3 Novel targeted post-ASCT consolidative options in development or approved for use in R/R HL (Continued)

\begin{tabular}{|c|c|c|c|}
\hline Targeted agent & Treatment setting & Efficacy & Safety \\
\hline Phase Ib/II study [76] & $\begin{array}{l}\mathrm{R} / \mathrm{R} \mathrm{HL} \\
\text { Median } 7.5 \text { prior therapies }(n=22)\end{array}$ & - CR 53\% & - Not reported \\
\hline $\begin{array}{l}\text { Phase I study } \\
\text { (NCT02259556) [77] }\end{array}$ & $\begin{array}{l}\mathrm{R} / \mathrm{R} \mathrm{HL} \\
\text { Heavily pretreated patients }(n=18)\end{array}$ & $\begin{array}{l}\text { - ORR 39\% } \\
\text { - Median PFS } 6 \text { months }\end{array}$ & - Grade $\geq 3$ AEs in 2 patients \\
\hline $\begin{array}{l}\text { Anti-LMP1/2 phase I study } \\
\text { (NCT00671164) [78] }\end{array}$ & $\mathrm{R} / \mathrm{R} \mathrm{HL} / \mathrm{NHL}(n=25)$ & $\begin{array}{l}\text { - 2-year EFS 50\% } \\
\text { - ORR 62\% } \\
\text { - CR 52\% }\end{array}$ & - Not reported \\
\hline
\end{tabular}

EPOCH etoposide, prednisone, vincristine, cyclophosphamide, and doxorubicin; NHL non Hodgkin lymphoma

EBMT panels recommend post-ASCT consolidation with brentuximab vedotin for a maximum of 16 cycles every 3 weeks, or until unacceptable toxicity or disease relapse (whichever occurs first) for brentuximab vedotin-naïve patients with $\mathrm{CHL}$ and one or more high-risk features as defined by the AETHERA study [36]. The panel do not recommend brentuximab vedotin post-ASCT consolidation in patients whose HL has shown signs of refractoriness to prior treatment with brentuximab vedotin; however, high-risk patients with relapsed disease and limited prior exposure to brentuximab vedotin ( $\sim-6$ cycles) prior to ASCT and no evidence of brentuximab-vedotinrefractory disease, were recommended for brentuximab vedotin consolidation.

\section{Novel consolidation options}

Following demonstration of the efficacy of brentuximab vedotin as consolidation in post-ASCT HL treatment, clinical studies to assess the efficacy of other anti-tumor agents, such as chemotherapies and checkpoint inhibitors, have been initiated. Novel therapies including ADCs, bispecific antibodies, and chimeric antigen receptor-modified $\mathrm{T}$ (CAR-T) cells are under investigation in R/R HL and other lymphomas, and may be an option for post-ASCT consolidation in the future. These are discussed briefly below.

ADCs One other ADC is in development for the treatment of $\mathrm{R} / \mathrm{R}$ HL. Camidanlumab tesirine is a human anti-CD25 monoclonal antibody conjugated to a potent pyrrolobenzodiazepine dimer toxin. A phase I, first-inhuman study reported an ORR of $81 \%$ in 26 patients with $\mathrm{R} / \mathrm{R} \mathrm{cHL}$ in the $45 \mu \mathrm{g} / \mathrm{kg}$ dose group, with $50 \% \mathrm{CR}$. Grade $\geq 3$ treatment-emergent adverse events were reported in $62 \%$ of patients (Table 3) [66].

Histone deacetylase inhibitors Panobinostat has been investigated as consolidation therapy for patients with HL in a phase III study that was discontinued due to poor accrual [67].

Nivolumab Preclinical analyses of lymphoma cells revealed the presence gene amplification of programmed cell death-1 (PD-1) ligand [79], raising the prospect of
anti-PD-1 agents as therapeutic agents in HL. Nivolumab, a fully human anti-PD-1 monoclonal antibody, was approved for use as monotherapy in adults with $\mathrm{R} / \mathrm{R} \mathrm{cHL}$ after ASCT and brentuximab vedotin based on the results of the phase II CheckMate 205 study [68, 69]. After a median follow-up of 18 months, ORR per independent review was $69 \%$, ranging from 65 to $73 \%$ across brentuximab vedotin-naïve and pre- and post-ASCT brentuximab vedotin-treated cohorts (Table 3 ). The safety and efficacy of nivolumab consolidation is being assessed in patients with HL, who are at risk of relapse or progression after receipt of an ASCT, in a single-arm phase II study (NCT03436862).

Pembrolizumab Pembrolizumab is a humanized antiPD-1 monoclonal antibody that is also being investigated in the relapsed HL post-ASCT consolidation setting [80]. In the phase II KEYNOTE-087 study of pembrolizumab in patients with $\mathrm{R} / \mathrm{R} \mathrm{cHL}$, ORR per independent review was $72 \%$ (95\% CI 65-78) after a median follow-up of 27.6 months [81]. The activity of pembrolizumab is also being assessed by Armand et al. in an ongoing multi-cohort phase II study in patients with R/R cHL who had achieved a CR or PR with first salvage chemotherapy (see Table 3) [70]; in contrast in the AETHERA study, patients were required to have achieved a $\mathrm{CR}, \mathrm{PR}$, or $\mathrm{SD}$ with salvage chemotherapy [65]. The primary endpoint, PFS at 18 months, was met, with a PFS rate of $82 \%$ for the evaluable patients; OS rate at 18 months was $100 \%$.

Other monoclonal antibodies In addition to PD-1, other targets under investigation include CD80, CD40, IL-13, LAG-3, TRAIL, CD25, and CD52. Early data for the anti-CD80 monoclonal antibody galiximab, and lucatumumab, which targets $\mathrm{CD} 40$, are not very promising, with ORRs around 10-14\% (Table 3) [71, 72]. Antibodies against CD25 and TRAIL are no longer under development [82].

Bispecific antibodies The bispecific antibody AFM13 targets CD30 and CD16a to recruit natural killer cells to CD30-positive malignancies. A monotherapy study in 26 heavily-treated $\mathrm{R} / \mathrm{R} \mathrm{HL}$ patients demonstrated mild 
efficacy (ORR 11.5\%, rising to $23 \%$ in the higher dose group; $n=13$ ) with a good safety profile [73]. A phase Ib study (KEYNOTE-206) combining AFM13 with pembrolizumab resulted in a much improved ORR of $88 \%$ (Table $3)$, which also compares favorably with rates seen with pembrolizumab alone [74].

CAR-T cells CAR-T cell therapies targeting CD30, CD123, and Epstein-Barr virus (EBV)-related proteins are in development for the treatment of $\mathrm{cHL}$, and are showing promising early results. Two US-based groups and one group in China have investigated CD30 CAR-T cell therapy in heavily-pretreated $\mathrm{R} / \mathrm{R} \mathrm{HL}$ with ORR rates of 67,63 , and 39\%, respectively (Table 3) [75-77]. A pivotal phase II study (NCT04268706) is being planned based on these encouraging results, and the US Food and Drug Administration granted Regenerative Medicine Advanced Therapy designation to this treatment on March 2, 2020. CAR-T cell therapy targeting the EBV antigens latent membrane protein 1 (LMP1) and LMP2 has also shown an encouraging ORR of $62 \%$, with $52 \% \mathrm{CR}$, in patients with $\mathrm{R} / \mathrm{R}$ lymphoma [78].

Post-ASCT radiotherapy $\mathrm{HL}$ is extremely sensitive to radiotherapy, even after multiple lines of chemotherapy; however, there is a lack of large prospective randomized studies to evaluate the role of post-ASCT consolidation radiotherapy. It is generally believed that radiation-naive patients with localized residual lymphoma post-salvage therapy or post-ASCT, could benefit from radiotherapy before signs of progressive systemic lymphoma develop. Retrospective analyses of patients treated with radiotherapy as a post-ASCT salvage or consolidation option in the clinic have shown variable effectiveness.

In the post-ASCT consolidation setting, radiotherapy has shown some promise with significant improvements in local control at 36 months post-ASCT in patients receiving radiotherapy compared with no radiotherapy (78\% vs $48 \%$, $p=0.02$ ) accompanied by limited toxicity [83]. Wilke et al. found more promising results in radiotherapy vs no radiotherapy regimens, with significant improvements in 2-year PFS ( $67 \%$ vs $42 \%, p<0.01)$, which could also be seen in patients with bulky disease (62\% vs $39 \%, p=0.02)$, Bsymptoms ( $48 \%$ vs $28 \%, p=0.05$ ), primary-refractory disease $(47 \%$ vs $32 \%, p=0.02)$, and those with a PR per pretransplant imaging ( $47 \%$ vs $32 \%, p=0.02$ ) [84]. However, neither of these analyses were able to demonstrate a significant improvement in OS with consolidative radiotherapy.

A single-institution analysis of 56 patients by Goda et al. found that in patients who had failed ASCT and received radiotherapy as a salvage option (salvage radiation therapy [sRT] alone in 34 patients and sRT plus chemotherapy in 22 patients), ORR was $84 \%$ ( $C R=36 \%$; $\mathrm{PR}=48 \%$ ) with a median OS of 40.8 months and 5-year
OS of 29\% [85]. The 2-year systemic PFS of $16 \%$ and overall disease control rate of $17 \%$ were disappointing, whereas local PFS at 2 years was $65 \%$, leading the authors to conclude that radiotherapy may be of use for palliation of incurable HL.

The paucity of consistent data supporting the use of post-ASCT radiotherapy are reflected in the heterogeneous adoption of this approach in European clinical practice, other than to treat localized disease.

\section{The challenge of demonstrating OS benefit in post-ASCT R/ $R H L$}

Demonstration of an OS benefit remains the ideal clinical endpoint in the oncological studies, representing the time from randomization until death. Salvage with HDC-ASCT is an effective approach that can be further improved by consolidation strategies in high-risk patients [65]; however, owing to the effectiveness of targeted therapies applied later in the disease course, it can take many years to accumulate enough survival events to demonstrate a statistically significant difference in OS between an experimental therapy and the placebo/control arm. In the AETHERA study, patients had lengthy post-ASCT PFS and OS, with some patients not relapsing during follow-up, i.e., potentially achieving a cure [65]. After a median follow-up of 5 years there were still insufficient $\mathrm{OS}$ events to draw any conclusions on the efficacy of brentuximab vedotin compared with placebo in terms of impact on OS [17], and this may be further complicated by the use of subsequent checkpoint inhibitors. Crucially, AETHERA permitted patients in the placebo arm to crossover to the brentuximab arm, resulting in $87 \%$ of patients in the placebo arm eventually receiving brentuximab vedotin monotherapy as a subsequent therapy, further confounding assessment of the impact of brentuximab vedotin on OS $[17,65]$.

Based on the challenges faced when using OS as an endpoint, the European Medicines Agency recommended that time to second subsequent therapy (TTSST) is used as a measure of ongoing disease control and an alternative to OS (Fig. 1). TTSST is defined as the time between treatment initiation and the start of the third line of treatment (second subsequent therapy) and can be used to assess continuous lymphoma control in patient populations at high risk of relapse, in which multiple additional therapies are often used $[86,87]$.

In a post hoc analysis of the AETHERA study at 5 years, significantly fewer patients in the brentuximab vedotin arm had a TTSST event compared with the placebo arm (36\% vs $46 \%, p<0.0001)$, implying that $64 \%$ of brentuximab vedotin-treated patients had not received $\geq 2$ subsequent therapies for $\mathrm{HL}$ or died, versus $54 \%$ in the placebo arm. Furthermore, subsequent transplants, 


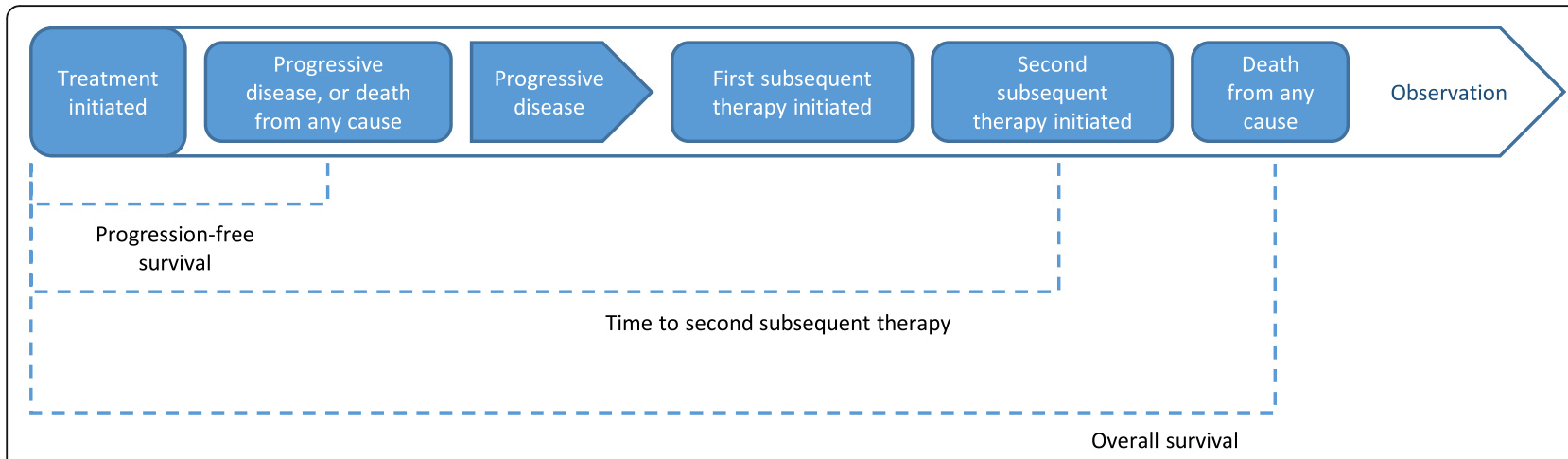

Fig. 1 Time to second subsequent therapy as an endpoint. Progression-free survival is defined as the length of time between treatment initiation and progressive disease or death, whichever occurs first. Overall survival is defined as the length of time during and after the treatment of a disease until death from any cause. In contrast, time to second subsequent therapy is defined as the length of time between treatment initiation and the start of the third line of treatment (second subsequent therapy)

including allo-SCT, were more common in the placebo arm than the brentuximab vedotin arm $[17,65]$.

\section{Discussion}

The advent of treatment strategies and the consideration of CMR before ASCT has improved patient outcomes in the R/R HL setting; however, a considerable number of patients continue to progress or relapse and display dismal post-transplant outcomes. Appropriate utilization of post-ASCT consolidation now appears to be a promising and widely-applicable strategy.

The introduction of brentuximab vedotin as a post-ASCT consolidation option has significantly improved patient outcomes in terms of PFS (30\% reduction in PFS events compared with placebo) and reduced the need for second subsequent therapy (36\% of brentuximab vedotin patients compared with $46 \%$ of placebo patients) [17]. The persistence of these outcomes after 5 years' follow-up demonstrate the benefits provided by brentuximab vedotin consolidation.

Currently, there is a paucity of published data and guidance on the utility of biomarkers in the R/R HL consolidation setting. The AETHERA study found that the benefit of brentuximab vedotin was more pronounced in patients with additional pre-ASCT risk factors for relapse. At 5 years, the HR for PFS was 0.42 (95\% CI $0.30-0.60)$ in patients with $\geq 2$ risk factors and 0.39 (95\% CI 0.26-0.60) in those with $\geq 3$ risk factors [17]. Therefore, prognostic factors should be considered when making treatment decisions in the R/R HL setting.

PET-positivity is a known negative prognostic factor; however, large-scale adequately-powered studies are required to obtain meaningful data to appropriately quantify the effect of the persistence and the magnitude of preASCT PET-positivity on the outcome of ASCT. In the AETHERA study, PET scans before ASCT were not mandated in the study protocol, reflecting clinical practice at the time [65]. Although PET scans were performed in approximately two-thirds of patients, objective criteria were not required for interpretation. The benefit of brentuximab vedotin appeared to be reduced in patients who were PET-negative before ASCT, according to a univariate analysis. The role of biomarkers in this setting is evolving. PET scans are now a requirement for all studies and metabolic tumor volume is also emerging as a promising new prognostic biomarker.

MRD has been used as surrogate parameter for treatment effectiveness in follicular lymphoma and MCL $[61,62,88-$ 91] and further studies are needed to demonstrate the clinical utility of MRD as a biomarker for personalization of HL consolidation strategies. Despite the paucity of evidence supporting routine use of MRD assessment as part of consolidation, the marked PFS benefit seen at 4 months in the AETHERA study, with continued benefit seen over the 5year follow-up period $[17,65]$ supports the rationale for extended use of consolidation therapy; in the case of the AETHERA study for up to 1 year after ASCT, to minimize the risk of relapse.

There are few publications characterizing the utility of similar markers in patients with HL [92-94]. Using a highly sensitive next-generation sequencing method, Oki et al. demonstrated the feasibility of identifying lymphomaspecific immunoglobulin gene segments in the peripheral blood of patients with cHL [92]. The authors postulated that this new blood-based method could be used to monitor disease burden and provide prognostic information for patients with cHL. In an exploratory analysis of patients enrolled in AETHERA, Bachanova et al. found that serum levels of thymus and activation-regulated chemokine may also be useful in identifying HL patients at increased risk of disease progression following ASCT treatment [94]. Moreover, Camus et al. determined that recurrent exportin 1 gene mutations in tumor and cell-free circulating DNA can be used as a novel biomarker in patients with cHL using a highly sensitive digital PCR technique [93]. Non-invasive 
methods utilizing cell-free circulating DNA to identify somatic mutations represent a promising advance in the management of HL. Molecular monitoring using cell-free DNA is emerging as a highly sensitive screening tool that has potential for future screening in hematologic malignancies $[95,96]$. More studies are needed to further elucidate these methods fully in patients with HL.

The impact of post-ASCT consolidation therapy on quality of life (QoL) needs to be carefully considered, as patients may have already experienced poor health-related QoL during HDC and ASCT [97, 98]. Peripheral neuropathy is a common $\mathrm{AE}$ with anti-microtubule-directed agents, and was the most frequently occurring $\mathrm{AE}$ with brentuximab vedotin in the AETHERA study [65]. Although $67 \%$ of patients in this study experienced peripheral neuropathy, of which the majority were sensory events, only $13 \%$ of patients experienced grade 3 events, and there were no grade 4 events. In a QoL analysis of the AETHERA study, there were no significant differences in mean European Quality of Life five dimensions scores between patients with and without peripheral neuropathy within the brentuximab vedotin arm at any time point [99].

Consensus recommendations from ASBMT, CIBMTR, and EBMT provide strong support for the use of brentuximab vedotin as consolidation/maintenance after ASCT in brentuximab vedotin-naïve patients with $\mathrm{CHL}$ based on data from the AETHERA study (grade A recommendation; there is good research-based evidence to support the recommendation) [36]. Authors did not provide any specific guidance on use of brentuximab vedotin salvage therapy and the expert panel also assigned a grade $\mathrm{C}$ recommendation (the recommendation is based on expert opinion and panel consensus) to the use of brentuximab vedotin as post-ASCT consolidation/maintenance in patients with limited prior exposure to brentuximab vedotin (4-6 cycles) [36]. With the approval of brentuximab vedotin (plus doxorubicin, vinblastine, and dacarbazine) in previously untreated patients with advanced $\mathrm{cHL}$ there will likely be future changes to the currently recommended post-transplant strategies.

\section{Conclusions}

In summary, post-ASCT consolidation (including radiotherapy) improves outcomes in patients with $\mathrm{R} / \mathrm{R} \mathrm{HL}$ who require ASCT, with early intervention providing the greatest benefits. More potent frontline and pre-ASCT salvage regimens also show promise in improving outcomes in this patient group, however, they have not yet been formally tested in phase III studies. Checkpoint inhibitors may be used for patients who have already received brentuximab vedotin. Approval of novel targeted agents is expected to further improve outcomes and provide additional treatment options in the coming age of personalized medicine.

\section{Abbreviations}

ABMT: Autologous bone marrow transplant; ABVD: Doxorubicin, bleomycin, vinblastine, and dacarbazine; ADC: Antibody-drug conjugate; AEs: Adverse events; alCE: Augmented ifosfamide, carboplatin, and etoposide; alloSCT: Allogeneic SCT; ASBMT: American Society for Blood and Marrow Transplantation; ASCT: Autologous stem cell transplantation;

ASHAP: Doxorubicin, methylprednisolone, high-dose cytarabine, and cisplatin; B + DHAP: Brentuximab vedotin + DHAP; BEACOPP: Bleomycin, etoposide, doxorubicin, cyclophosphamide, vincristine, procarbazine, and prednisone; BEAM: Carmustine, etoposide, cytarabine, and melphalan;

BeGEV: Bendamustine, gemcitabine, and vinorelbine; BrESHAP: Brentuximab vedotin + ESHAP; CAR-T: Chimeric antigen receptor-modified T cell; CD30: Cluster of differentiation 30; CHL: Classical HL; CIBMTR: Center for International Blood and Marrow Transplant Research; CMR: Complete metabolic response; CR: Complete response; Dexa-BEAM: Dexamethasone plus BEAM; DHAP: Dexamethasone, high-dose cytarabine, and cisplatin; EBMT: European Group for Blood and Marrow Transplantation; EBV: EpsteinBarr virus; EFS: Event-free survival; EPOCH: Etoposide, prednisone, vincristine, cyclophosphamide, and doxorubicin; ESHAP: Etoposide, methylprednisolone, high-dose cytarabine, and cisplatin; ESMO: European Society for Medical Oncology; FFTF: Freedom from treatment failure; GDP: Gemcitabine, dexamethasone, and cisplatin; GELTAMO: Grupo Español de Linfomas y Trasplantes de Médula Ósea; GemOx: Gemcitabine and oxaliplatin; GHSG: German Hodgkin Study Group; GVD: Gemcitabine, vinorelbine, and pegylated liposomal doxorubicin; HDC: High-dose chemotherapy; HL: Hodgkin lymphoma; HR: Hazard ratio; ICE: Ifosfamide, carboplatin, and etoposide; IGEV: Ifosfamide, gemcitabine, vinorelbine, and prednisolone; IVE: Ifosfamide, etoposide, and epirubicin; IVOx: Ifosfamide, etoposide, and oxaliplatin; LMP1: Latent membrane protein 1; LYSA: Lymphoma Study Association; MCL: Mantle cell lymphoma; MINE: Mitoguazone, ifosfamide, vinorelbine, and etoposide; MRD: Minimal residual disease; NCCN: National Comprehensive Cancer Network; NHL: Non Hodgkin lymphoma; NR: Not reported; ORR: Objective response rate; OS: Overall survival; PCR: Polymerase chain reaction; PD-1: Programmed cell death-1; PET: Positron-emission tomography; PFS: Progression-free survival; PR: Partial remission; pts: Patients; Q3W: Every 3 weeks; QoL: Quality of life; R/R: Relapsed/refractory; SCT: Stem cell transplantation; SD: Stable disease; SFGM: Société Francaise de Greffe de Moelle; TTSST: Time to second subsequent therapy

\section{Acknowledgments}

Writing assistance for this manuscript was provided by Helen Kitchen and Hedley Coppock, of FireKite, an Ashfield company, part of UDG Healthcare plc, which was funded by Millennium Pharmaceuticals Inc. and complied with Good Publication Practice 3 ethical guidelines (Battisti, et al. Ann Intern Med 2015;163:461-4).

\section{Authors' contributions}

AS contributed to conception and design, data analysis and interpretation, drafting of and writing the manuscript. MA contributed to conception and design, and drafting of the manuscript. PB contributed to data analysis and interpretation, and writing of the manuscript. MS contributed to conception and design, collection and assembly of data, data analysis and interpretation, and drafting of and writing the manuscript. CG contributed to conception and design, collection and assembly of data, data analysis and interpretation, and drafting of and writing the manuscript. TV contributed to conception and design, and writing of the manuscript. PLZ contributed to data analysis and interpretation, and writing of the manuscript. JW contributed to conception and design, and drafting the manuscript. All authors read and approved the final manuscript, and agree to be accountable for all aspects of the work.

\section{Funding}

Writing assistance was funded by Millennium Pharmaceuticals Inc. (see Acknowledgements section for further details).

Availability of data and materials Not applicable.

Ethics approval and consent to participate Not applicable. 


\section{Consent for publication}

Not applicable.

\section{Competing interests}

AS reports research funding from Roche; personal financial interests in Takeda, Gilead, Celgene, Novartis, and Kite Gilead; and receipt of other payments from: Takeda, BMS, MSD, Roche, Celgene, Janssen, Novartis, Kite Gilead, Sanofi, Daiichi, and GenMab. MA reports research funding and other payments from Takeda. PB reports receipt of research funding from Takeda Oncology. MS reports research funding form Gilead and receipt of other payments from: Roche, Celgene, Kite Gilead, and Abbvie. CG reports no conflicts of interest. TV reports receipt of other payments from BMS, Genesis Pharmaceuticals, Roche, Takeda, Novartis, Gilead, Merck, Astellas, and Winmedica. PLZ reports receipt of other payments from: MSD, Verastem, Roche, Servier, Celgene, Novartis, Gilead, BMS, Portola, Morphosys, Janssen, Hikma and Celltrion. JW reports research funding from: Roche, GSK, Novartis, Takeda, Janssen; and receipt of other payments from Roche, Celgene, Takeda, Janssen, Servier, Amgen, BMS, Abbvie, Novartis, and Gilead.

\section{Author details}

'Hematology Department, Hematopoietic Stem Cell Transplant Programme, Institut Català d'Oncologia-Hospital Duran i Reynals, Gran Via de l'Hospitalet, 199 - 203, 08908 Barcelona, Spain. ${ }^{2}$ Institut d'Investigació Biomèdica de Bellvitge (IDIBELL), Universitat de Barcelona (UB), Barcelona, Spain. ${ }^{3}$ Department of Hematology, Université catholique de Louvain, $\mathrm{CHU}$ UCL Namur, Yvoir, Belgium. ${ }^{4}$ Department of Internal Medicine I, University Hospital Cologne, Cologne, Germany. ${ }^{5}$ Department of Hematology, Instituto Português de Oncologia - Francisco Gentil, Lisbon, Portugal. ${ }^{6}$ Institut d'Hématologie, Hôpital Saint Louis, Paris, France. 'Department of Haematology and Bone Marrow Transplantation, National and Kapodistrian University of Athens, Laikon General Hospital, Athens, Greece. ${ }^{8}$ Azienda Ospedaliero-Universitaria di Bologna, Bologna, Italy. Istituto di Ematologia "Seràgnoli", Dipartimento di Medicina Specialistica, Diagnostica e Sperimentale Università degli Studi, Bologna, Italy. ${ }^{10}$ Department of Lymphoid Malignancies, Maria Sklodowska-Curie Institute Oncology Center, Warszawa, Poland.

\section{Received: 19 August 2020 Accepted: 23 October 2020} Published online: 10 November 2020

\section{References}

1. Lim SH, Johnson PWM. Optimizing therapy in advanced-stage Hodgkin lymphoma. Blood. 2018;131:1679-88.

2. Shanbhag S, Ambinder RF. Hodgkin lymphoma: a review and update on recent progress. CA Cancer J Clin. 2018;68:116-32.

3. Armitage JO. Early-stage Hodgkin's lymphoma. N Engl J Med. 2010;363:653-62.

4. lannitto E, Minardi V, Gobbi PG, Calvaruso G, Tripodo C, Marcheselli L, et al. Response-guided ABVD chemotherapy plus involved-field radiation therapy for intermediate-stage Hodgkin lymphoma in the pre-positron emission tomography era: a Gruppo Italiano Studio Linfomi (GISL) prospective trial. Clin Lymphoma Myeloma. 2009;9:138-44.

5. Merli F, Luminari S, Gobbi PG, Cascavilla N, Mammi C, llariucci F, et al. Longterm results of the HD2000 trial comparing ABVD versus BEACOPP versus COPP-EBV-CAD in untreated patients with advanced Hodgkin lymphoma: a study by Fondazione Italiana Linfomi. J Clin Oncol. 2016;34:1175-81.

6. Borchmann P, Goergen H, Kobe C, Lohri A, Greil R, Eichenauer DA, et al. PETguided treatment in patients with advanced-stage Hodgkin's lymphoma (HD18): final results of an open-label, international, randomised phase 3 trial by the German Hodgkin Study Group. Lancet. 2018;390:2790-802.

7. Casasnovas RO, Bouabdallah R, Brice P, Lazarovici J, Ghesquieres H, Stamatoullas A, et al. PET-adapted treatment for newly diagnosed advanced Hodgkin lymphoma (AHL2011): a randomised, multicentre, non-inferiority, phase 3 study. Lancet Oncol. 2019;20:202-15.

8. Philip T, Guglielmi C, Hagenbeek A, Somers R, Van Der Lelie H, Bron D, et al. Autologous bone marrow transplantation as compared with salvage chemotherapy in relapses of chemotherapy-sensitive non-Hodgkin's lymphoma. N Engl J Med. 1995;333:1540-5.

9. Schmitz N, Pfistner B, Sextro M, Sieber M, Carella AM, Haenel M, et al. Aggressive conventional chemotherapy compared with high-dose chemotherapy with autologous haemopoietic stem-cell transplantation for relapsed chemosensitive Hodgkin's disease: a randomised trial. Lancet. 2002;359:2065-71.
10. NCCN (2019). NCCN clinical practice guidelines in oncology (NCCN guidelines ${ }^{\circledast}$ ) for Hodgkin lymphoma V.2.2019. https://www.nccn.org/ professionals/physician_gls/pdf/hodgkins.pdf. Accessed 1 Oct 2019.

11. Eichenauer DA, Aleman BMP, Andre M, Federico M, Hutchings M, Illidge T, et al. Hodgkin lymphoma: ESMO Clinical Practice Guidelines for diagnosis, treatment and follow-up. Ann Oncol. 2018;29:iv19-29.

12. Kaloyannidis P, Hertzberg M, Webb K, Zomas A, Schrover R, Hurst M, et al. Brentuximab vedotin for the treatment of patients with relapsed or refractory Hodgkin lymphoma after autologous stem cell transplantation. $\mathrm{Br}$ J Haematol. 2019;188:540-9.

13. Kewalramani T, Nimer SD, Zelenetz AD, Malhotra S, Qin J, Yahalom J, et al. Progressive disease following autologous transplantation in patients with chemosensitive relapsed or primary refractory Hodgkin's disease or aggressive non-Hodgkin's lymphoma. Bone Marrow Transplant. 2003;32:673-9.

14. Lancet JE, Rapoport AP, Brasacchio R, Eberly S, Raubertas RF, Linder T, et al. Autotransplantation for relapsed or refractory Hodgkin's disease: long-term follow-up and analysis of prognostic factors. Bone Marrow Transplant. 1998; 22:265-71.

15. Sweetenham JW, Carella AM, Taghipour G, Cunningham D, Marcus R, Della Volpe A, et al. High-dose therapy and autologous stem-cell transplantation for adult patients with Hodgkin's disease who do not enter remission after induction chemotherapy: results in 175 patients reported to the European Group for Blood and Marrow Transplantation. Lymphoma Working Party. J Clin Oncol. 1999:17:3101-9.

16. Moskowitz AJ, Schoder H, Yahalom J, Mccall SJ, Fox SY, Gerecitano J, et al. PET-adapted sequential salvage therapy with brentuximab vedotin followed by augmented ifosamide, carboplatin, and etoposide for patients with relapsed and refractory Hodgkin's lymphoma: a non-randomised, openlabel, single-centre, phase 2 study. Lancet Oncol. 2015;16:284-92.

17. Moskowitz CH, Walewski J, Nademanee A, Masszi T, Agura E, Holowiecki J, et al. Five-year PFS from the AETHERA trial of brentuximab vedotin for Hodgkin lymphoma at high risk of progression or relapse. Blood. 2018;132: 2639-42.

18. Linch DC, Winfield D, Goldstone AH, Moir D, Hancock B, Mcmillan A, et al. Dose intensification with autologous bone-marrow transplantation in relapsed and resistant Hodgkin's disease: results of a BNLI randomised trial. Lancet. 1993;341:1051-4.

19. Rancea M, Monsef I, Von Tresckow B, Engert A, Skoetz N. High-dose chemotherapy followed by autologous stem cell transplantation for patients with relapsed/refractory Hodgkin lymphoma. Cochrane Database Syst Rev. 2013;(6):Cd009411.

20. Josting A, Rudolph C, Reiser M, Mapara M, Sieber M, Kirchner HH, et al. Time-intensified dexamethasone/cisplatin/cytarabine: an effective salvage therapy with low toxicity in patients with relapsed and refractory Hodgkin's disease. Ann Oncol. 2002;13:1628-35.

21. Josting A, Rudolph C, Mapara M, Glossmann JP, Sieniawski M, Sieber M, et al. Cologne high-dose sequential chemotherapy in relapsed and refractory Hodgkin lymphoma: results of a large multicenter study of the German Hodgkin Lymphoma Study Group (GHSG). Ann Oncol. 2005;16:116-23.

22. Rodriguez J, Rodriguez MA, Fayad L, Mclaughlin P, Swan F, Sarris A, et al. ASHAP: a regimen for cytoreduction of refractory or recurrent Hodgkin's disease. Blood. 1999;93:3632-6.

23. Aparicio J, Segura A, Garcera S, Oltra A, Santaballa A, Yuste A, et al. ESHAP is an active regimen for relapsing Hodgkin's disease. Ann Oncol. 1999;10:593-5.

24. Labrador J, Cabrero-Calvo M, Perez-Lopez E, Mateos MV, Vazquez L, Caballero MD, et al. ESHAP as salvage therapy for relapsed or refractory Hodgkin's lymphoma. Ann Hematol. 2014;93:1745-53.

25. Ferme C, Bastion Y, Lepage E, Berger F, Brice P, Morel P, et al. The MINE regimen as intensive salvage chemotherapy for relapsed and refractory Hodgkin's disease. Ann Oncol. 1995;6:543-9.

26. Moskowitz CH, Nimer SD, Zelenetz AD, Trippett T, Hedrick EE, Filippa DA, et al. A 2-step comprehensive high-dose chemoradiotherapy second-line program for relapsed and refractory Hodgkin disease: analysis by intent to treat and development of a prognostic model. Blood. 2001;97:616-23.

27. Hertzberg MS, Crombie C, Benson W, Taper J, Gottlieb D, Bradstock KF. Outpatient fractionated ifosfamide, carboplatin and etoposide as salvage therapy in relapsed and refractory non-Hodgkin's and Hodgkin's lymphoma. Ann Oncol. 2006;17(Suppl 4):iv25-30.

28. Proctor SJ, Jackson GH, Lennard A, Angus B, Wood K, Lucraft HL, et al. Strategic approach to the management of Hodgkin's disease incorporating salvage therapy with high-dose ifosfamide, etoposide and epirubicin: a 
Northern Region Lymphoma Group study (UK). Ann Oncol. 2003;14(Suppl 1):i47-50.

29. Sibon D, Ertault M, Al Nawakil C, De Bazelaire C, Franchi P, Briere J, et al. Combined ifosfamide, etoposide and oxalipatin chemotherapy, a lowtoxicity regimen for first-relapsed or refractory Hodgkin lymphoma after ABVD/EBVP: a prospective monocentre study on 34 patients. Br J Haematol. 2011;153:191-8

30. Bartlett NL, Niedzwiecki D, Johnson JL, Friedberg JW, Johnson KB, Van Besien $\mathrm{K}$, et al. Gemcitabine, vinorelbine, and pegylated liposomal doxorubicin (GVD), a salvage regimen in relapsed Hodgkin's lymphoma: CALGB 59804. Ann Oncol. 2007;18:1071-9.

31. Santoro A, Magagnoli M, Spina M, Pinotti G, Siracusano L, Michieli M, et al. Ifosfamide, gemcitabine, and vinorelbine: a new induction regimen for refractory and relapsed Hodgkin's lymphoma. Haematologica. 2007;92:35-41.

32. Baetz T, Belch A, Couban S, Imrie K, Yau J, Myers R, et al. Gemcitabine, dexamethasone and cisplatin is an active and non-toxic chemotherapy regimen in relapsed or refractory Hodgkin's disease: a phase II study by the National Cancer Institute of Canada Clinical Trials Group. Ann Oncol. 2003;14:1762-7.

33. Gutierrez A, Rodriguez J, Martinez-Serra J, Gines J, Paredes P, Garcia F, et al. Gemcitabine and oxaliplatinum: an effective regimen in patients with refractory and relapsing Hodgkin lymphoma. Oncol Targets Ther. 2014;7:2093-100.

34. Santoro A, Mazza R, Pulsoni A, Re A, Bonfichi M, Zilioli VR, et al. Bendamustine in combination with gemcitabine and vinorelbine is an effective regimen as induction chemotherapy before autologous stem-cell transplantation for relapsed or refractory Hodgkin lymphoma: final results of a multicenter phase II study. J Clin Oncol. 2016;34:3293-9.

35. Moskowitz CH, Matasar MJ, Zelenetz AD, Nimer SD, Gerecitano J, Hamlin P, et al. Normalization of pre-ASCT, FDG-PET imaging with second-line, noncross-resistant, chemotherapy programs improves event-free survival in patients with Hodgkin lymphoma. Blood. 2012;119:1665-70.

36. Kanate AS, Kumar A, Dreger P, Dreyling M, Le Gouill S, Corradini P, et al. Maintenance therapies for Hodgkin and non-Hodgkin lymphomas after autologous transplantation: a consensus project of ASBMT, CIBMTR, and the Lymphoma Working Party of EBMT. JAMA Oncol. 2019;5:715-22.

37. Moskowitz CH, Kewalramani T, Nimer SD, Gonzalez M, Zelenetz AD, Yahalom J. Effectiveness of high dose chemoradiotherapy and autologous stem cell transplantation for patients with biopsy-proven primary refractory Hodgkin's disease. Br J Haematol. 2004;124:645-52.

38. Sirohi B, Cunningham D, Powles R, Murphy F, Arkenau T, Norman A, et al. Long-term outcome of autologous stem-cell transplantation in relapsed or refractory Hodgkin's lymphoma. Ann Oncol. 2008;19:1312-9.

39. Moskowitz C. Novel agents and strategies in transplant-eligible patients with relapsed and refractory Hodgkin lymphoma. Hematology Am Soc Hematol Educ Program. 2016;2016:331-8.

40. Josting A, Muller H, Borchmann P, Baars JW, Metzner B, Dohner H, et al. Dose intensity of chemotherapy in patients with relapsed Hodgkin's lymphoma. J Clin Oncol. 2010;28:5074-80.

41. Moskowitz AJ, Hamlin PA Jr, Perales MA, Gerecitano J, Horwitz SM, Matasar $\mathrm{MJ}$, et al. Phase II study of bendamustine in relapsed and refractory Hodgkin Iymphoma. J Clin Oncol. 2013;31:456-60.

42. Zinzani PL, Derenzini E, Pellegrini C, Celli M, Broccoli A, Argnani L. Bendamustine efficacy in Hodgkin lymphoma patients relapsed/refractory to brentuximab vedotin. Br J Haematol. 2013;163:681-3.

43. Anastasia A, Carlo-Stella C, Corradini P, Salvi F, Rusconi C, Pulsoni A, et al. Bendamustine for Hodgkin lymphoma patients failing autologous or autologous and allogeneic stem cell transplantation: a retrospective study of the Fondazione Italiana Linfomi. Br J Haematol. 2014;166:140-2.

44. Takeda Pharmaceuticals. (Adcetris) summary of product characteristics. 2018. https://www.ema.europa.eu/en/documents/product-information/adcetrisepar-product-information_en.pdf. Accessed 1 Jan 2020.

45. Younes A, Gopal AK, Smith SE, Ansell SM, Rosenblatt JD, Savage K, et al. Results of a pivotal phase II study of brentuximab vedotin for patients with relapsed or refractory Hodgkin's lymphoma. J Clin Oncol. 2012;30:2183-9.

46. Chen R, Gopal AK, Smith SE, Ansell SM, Rosenblatt JD, Savage KJ, et al. Fiveyear survival and durability results of brentuximab vedotin in patients with relapsed or refractory Hodgkin lymphoma. Blood. 2016;128:1562-6.

47. Walewski J, Hellmann A, Siritanaratkul N, Ozsan GH, Ozcan M, Chuncharunee $\mathrm{S}$, et al. Prospective study of brentuximab vedotin in relapsed/refractory Hodgkin lymphoma patients who are not suitable for stem cell transplant or multi-agent chemotherapy. Br J Haematol. 2018;183: 400-10.
48. Hagenbeek A, Zijlstra JM, Plattel WJ, Morschauser F, Lugtenburg PJ, Brice P, et al. Combining brentuximab vedotin with DHAP as salvage treatment in relapsed/refractory Hodgkin lymphoma: the phase II HOVON/LLPC transplant BRaVE study. Blood. 2018;132(Suppl 1):abstract 2923.

49. Garcia-Sanz R, Sureda A, De La Cruz F, Canales M, Gonzalez AP, Pinana JL, et al. Brentuximab vedotin and ESHAP is highly effective as second-line therapy for Hodgkin lymphoma patients (long-term results of a trial by the Spanish GELTAMO group). Ann Oncol. 2019;30:612-20.

50. Cassaday RD, Fromm JR, Cowan AJ, Smith SD, Libby EN, Philip M, et al. Radiographic and high-throughput sequencing (HTS)-based response assessment after brentuximab vedotin (BV) plus ifosfamide, carboplatin, and etoposide (ICE) for relapsed/refractory (rel/ref) classical Hodgkin lymphoma (cHL): updated results of a phase I/II trial. Blood. 2017;130(Suppl 1):abstract 2806.

51. Stamatoullas A, Ghesquieres H, Clement filliatre L, Quittet P, Morschhauser F, Ribrag $V$, et al. Brentuximab vedotin in first refractory/relapsed classical Hodgkin lymphoma patients treated by chemotherapy (ICE) before autologous transplantation. Final analysis of phase II study. Blood. 2019; 134(Suppl 1):abstract 132.

52. Chen R, Palmer JM, Martin P, Tsai N, Kim Y, Chen BT, et al. Results of a multicenter phase II trial of brentuximab vedotin as second-line therapy before autologous transplantation in relapsed/refractory Hodgkin lymphoma. Biol Blood Marrow Transplant. 2015;21:2136-40.

53. Lacasce AS, Bociek RG, Sawas A, Caimi P, Agura E, Matous J, et al. Brentuximab vedotin plus bendamustine: a highly active first salvage regimen for relapsed or refractory Hodgkin lymphoma. Blood. 2018;132:408.

54. Herrera AF, Moskowitz AJ, Bartlett NL, Vose JM, Ramchandren R, Feldman TA, et al. Interim results of brentuximab vedotin in combination with nivolumab in patients with relapsed or refractory Hodgkin lymphoma Blood. 2018;131:1183-94.

55. Morschhauser F, Brice P, Ferme C, Divine M, Salles G, Bouabdallah R, et al. Risk-adapted salvage treatment with single or tandem autologous stem-cell transplantation for first relapse/refractory Hodgkin's lymphoma: results of the prospective multicenter H96 trial by the GELA/SFGM study group. J Clin Oncol. 2008;26:5980-7.

56. Sibon D, Morschhauser F, Resche-Rigon M, Ghez D, Dupuis J, Marcais A, et al. Single or tandem autologous stem-cell transplantation for firstrelapsed or refractory Hodgkin lymphoma: 10-year follow-up of the prospective H96 trial by the LYSA/SFGM-TC study group. Haematologica. 2016;101:474-81.

57. Smith EP, Li H, Friedberg JW, Constine LS, Rimsza LM, Cook JR, et al. Tandem autologous hematopoietic cell transplantation for patients with primary progressive or recurrent Hodgkin lymphoma: a SWOG and blood and marrow transplant clinical trials network phase II trial (SWOG S0410/ BMT CTN 0703). Biol Blood Marrow Transplant. 2018;24:700-7.

58. Deau B, Amorim S, Perrot A, Quittet P, Cornillon J, Chaoui D, et al. Tandem haematopoietic stem cell transplantation for high risk relapsed/refractory Hodgkin lymphoma: a LYSA study. Br J Haematol. 2018;181:341-9.

59. Bento L, Boumendil A, Fine H, Khvedelidze I, Blaise D, Fegueux N, et al. S1622 tandem autologous-reduced intensity allogeneic stem cell transplantation in high-risk relapsed Hodgkin lymphoma: a retrospective study of the LWP-EBMT. HemaSphere. 2019;3:749-50.

60. Brockelmann PJ, Muller H, Casasnovas O, Hutchings M, Von Tresckow B, Jurgens $\mathrm{M}$, et al. Risk factors and a prognostic score for survival after autologous stem-cell transplantation for relapsed or refractory Hodgkin lymphoma. Ann Oncol. 2017;28:1352-8.

61. Pettengell R, Schmitz N, Gisselbrecht C, Smith G, Patton WN, Metzner B, et al. Rituximab purging and/or maintenance in patients undergoing autologous transplantation for relapsed follicular lymphoma: a prospective randomized trial from the lymphoma working party of the European group for blood and marrow transplantation. J Clin Oncol. 2013;31:1624-30.

62. Bourcier J, Gastinne T, Leux C, Moreau A, Bossard C, Mahe B, et al. Rituximab maintenance after autologous stem cell transplantation prolongs response duration in non-naive rituximab follicular lymphoma patients: a single institution experience. Ann Hematol. 2016;95:1287-93.

63. Le Gouill S, Thieblemont C, Oberic L, Moreau A, Bouabdallah K, Dartigeas C, et al. Rituximab after autologous stem-cell transplantation in mantle-cell lymphoma. N Engl J Med. 2017;377:1250-60.

64. Chidiac A, Massoud R, Haidar M, Fares E, Bazabachi A, Cheikh JE. Posttransplant brentuximab maintenance appears more effective than post- 
transplant salvage brentuximab for relapsed/refractory Hogkin's lymphoma. Blood. 2016;128(22):abstract 5357.

65. Moskowitz CH, Nademanee A, Masszi T, Agura E, Holowiecki J, Abidi MH, et al. Brentuximab vedotin as consolidation therapy after autologous stemcell transplantation in patients with Hodgkin's lymphoma at risk of relapse or progression (AETHERA): a randomised, double-blind, placebo-controlled, phase 3 trial. Lancet. 2015;385:1853-62.

66. Hamadani M, Collins GP, Samaniego F, Spira Al, Davies A, Radford J, et al. Phase 1 study of Adct-301 (camidanlumab tesirine), a novel pyrrolobenzodiazepine-based antibody drug conjugate, in relapsed/ refractory classical Hodgkin lymphoma. Blood. 2018;132(Suppl 1):928.

67. Von Tresckow B, Morschhauser F, Szer J, Eichenauer DA, Abramson JS, Sureda A, et al. Panobinostat consolidation in patients with Hodgkin lymphoma at risk for relapse after high dose chemotherapy and autologous stem cell transplant: final results after early trial discontinuation. Leuk Lymphoma. 2017;58:222-5.

68. Armand P, Engert A, Younes A, Fanale M, Santoro A, Zinzani PL, et al. Nivolumab for relapsed/refractory classic Hodgkin lymphoma after failure of autologous hematopoietic cell transplantation: extended follow-up of the multicohort single-arm phase II CheckMate 205 trial. J Clin Oncol. 2018;36: 1428-39.

69. Bristol-Myers Squibb. (Opdivo) summary of product characteistics. 2015. https://www.ema.europa.eu/en/documents/product-information/opdivoepar-product-information_en.pdf. Accessed 1 Jan 2020.

70. Armand P, Chen YB, Redd RA, Joyce RM, Bsat J, Jeter E, et al. PD-1 blockade with pembrolizumab for classical Hodgkin lymphoma after autologous stem cell transplantation. Blood. 2019;134:22-9.

71. Smith SM, Schoder H, Johnson JL, Jung SH, Bartlett NL, Cheson BD, et al. The anti-CD80 primatized monoclonal antibody, galiximab, is welltolerated but has limited activity in relapsed Hodgkin lymphoma: cancer and Leukemia Group B 50602 (Alliance). Leuk Lymphoma. 2013; 54:1405-10.

72. Fanale M, Assouline S, Kuruvilla J, Solal-Celigny P, Heo DS, Verhoef G, et al. Phase IA/II, multicentre, open-label study of the CD40 antagonistic monoclonal antibody lucatumumab in adult patients with advanced nonHodgkin or Hodgkin lymphoma. Br J Haematol. 2014;164:258-65.

73. Rothe A, Sasse S, Topp MS, Eichenauer DA, Hummel H, Reiners KS, et al. A phase 1 study of the bispecific anti-CD30/CD16A antibody construct AFM13 in patients with relapsed or refractory Hodgkin lymphoma. Blood. 2015;125:4024-31.

74. Ansell SM, Bartlett NL, Chen RW, Herrera A, Domingo-Domenech E, Mehta $A$, et al. Investigating safety and preliminary efficacy of AFM13 plus pembrolizumab in patients with relapsed/refractory Hodgkin lymphoma after brentuximab vedotin failure. Hematol Oncol. 2019;37:128.

75. Ramos CA, Torrano V, Bilgi M, Gerken C, Dakhova O, Mei Z, et al. CD30chimeric antigen receptor (CAR) T cells for therapy of Hodgkin Lymphoma (HL). Hematol Oncol. 2019;37:119.

76. Grover NS, Park SI, Ivanova A, Eldridge P, Mckay K, Cheng C, et al. A phase $\mathrm{lb} / \mathrm{ll}$ study of anti-CD30 chimeric antigen receptor T cells for relapsed/ refractory CD30+ lymphomas. Biol Blood Marrow Transplant. 2019;25:83.

77. Wang CM, Wu ZQ, Wang Y, Guo YL, Dai HR, Wang XH, et al. Autologous T cells expressing CD30 chimeric antigen receptors for relapsed or refractory Hodgkin lymphoma: an open-label phase I trial. Clin Cancer Res. 2017;23: 1156-66.

78. Bollard CM, Gottschalk S, Torrano V, Diouf O, Ku S, Hazrat Y, et al. Sustained complete responses in patients with lymphoma receiving autologous cytotoxic T lymphocytes targeting Epstein-Barr virus latent membrane proteins. J Clin Oncol. 2014:32:798-808.

79. Green MR, Monti S, Rodig SJ, Juszczynski P, Currie T, O'donnell E, et al. Integrative analysis reveals selective 9p24.1 amplification, increased PD-1 ligand expression, and further induction via JAK2 in nodular sclerosing Hodgkin lymphoma and primary mediastinal large B-cell lymphoma. Blood. 2010;116:3268-77.

80. Merck Sharp \& Dohme B.V. (Keytruda) summary of product characteristics. 2015. https://www.ema.europa.eu/en/documents/product-information/ keytruda-epar-product-information_en.pdf. Accessed 1 Jan 2020.

81. Chen R, Zinzani PL, Lee HJ, Armand P, Johnson NA, Brice P, et al. Pembrolizumab in relapsed or refractory Hodgkin lymphoma: 2-year followup of KEYNOTE-087. Blood. 2019;134:1144-53.

82. Engert A, Diehl V, Schnell R, Radszuhn A, Hatwig MT, Drillich S, et al. A phase-I study of an anti-CD25 ricin A-chain immunotoxin (RFT5-SMPT-dgA) in patients with refractory Hodgkin's lymphoma. Blood. 1997;89:403-10.
83. Jauhari S, Plastaras J, Lukens J, Maity A, Schuster SJ, Nasta SD. Consolidative radiation therapy following autologous transplantation in relapsed or refractory Hodgkin lymphoma. Blood. 2015;126(23):abstract 3195.

84. Wilke C, Cao Q, Dusenbery KE, Bachanova V, Lazaryan A, Lee CK, et al. Role of consolidative radiation therapy after autologous hematopoietic cell transplantation for the treatment of relapsed or refractory Hodgkin lymphoma. Int J Radiat Oncol Biol Phys. 2017;99:94-102.

85. Goda JS, Massey C, Kuruvilla J, Gospodarowicz MK, Wells W, Hodgson DC, et al. Role of salvage radiation therapy for patients with relapsed or refractory Hodgkin lymphoma who failed autologous stem cell transplant. Int J Radiat Oncol Biol Phys. 2012;84:e329-35.

86. European Medicines Agency. Appendix 1 to the guideline on the evaluation of anticancer medicinal products in man - methodological consideration for using progression-free survival (PFS) or disease-free survival (DFS) in confirmatory trials. Revision 1. 2013. https://www.ema.europa.eu/en/ appendix-1-guideline-evaluation-anticancer-medicinal-products-manmethodological-consideration-using. Accessed 1 May 2019.

87. Matulonis UA, Oza AM, Ho TW, Ledermann JA. Intermediate clinical endpoints: a bridge between progression-free survival and overall survival in ovarian cancer trials. Cancer. 2015:121:1737-46.

88. Ehinger M, Pettersson L. Measurable residual disease testing for personalized treatment of acute myeloid leukemia. Apmis. 2019;127:337-51.

89. Molica S, Giannarelli D, Montserrat E. Minimal residual disease and survival outcomes in patients with chronic lymphocytic leukemia: a systematic review and meta-analysis. Clin Lymphoma Myeloma Leuk. 2019;19:423-30.

90. Chase ML, Armand P. Minimal residual disease in non-Hodgkin lymphoma current applications and future directions. Br J Haematol. 2018;180:177-88.

91. Landgren O, Lu SX, Hultcrantz M. MRD testing in multiple myeloma: the main future driver for modern tailored treatment. Semin Hematol. 2018;55: 44-50.

92. Oki Y, Neelapu SS, Fanale M, Kwak LW, Fayad L, Rodriguez MA, et al. Detection of classical Hodgkin lymphoma specific sequence in peripheral blood using a next-generation sequencing approach. $\mathrm{Br} J$ Haematol. 2015; 169:689-93.

93. Camus V, Stamatoullas A, Mareschal S, Viailly PJ, Sarafan-Vasseur N, Bohers E, et al. Detection and prognostic value of recurrent exportin 1 mutations in tumor and cell-free circulating DNA of patients with classical Hodgkin lymphoma. Haematologica. 2016;101:1094-101.

94. Bachanova V, Carella A, Masszi T, Holowiecki J, Viviani S, Huebner D, et al. Evaluation of serum tarc levels in patients at risk of progression following autologous stem cell transplant for Hodgkin lymphoma: results from the AETHERA trial. Haematologica. 2016;101(Suppl 5):poster P060.

95. Rossi D, Condoluci A, Spina V, Gaidano G. Methods for measuring ctDNA in lymphomas. Methods Mol Biol. 1881;2019:253-65.

96. Lenaerts L, Vandenberghe P, Brison N, Che H, Neofytou M, Verheecke M, et al. Genomewide copy number alteration screening of circulating plasma DNA: potential for the detection of incipient tumors. Ann Oncol. 2019;30: 85-95.

97. Brandt J, Dietrich S, Meissner J, Neben K, Ho AD, Witzens-Harig M. Quality of life of long-term survivors with Hodgkin lymphoma after high-dose chemotherapy, autologous stem cell transplantation, and conventional chemotherapy. Leuk Lymphoma. 2010;51:2012-20.

98. Minn AY, Riedel E, Halpern J, Johnston LJ, Horning SJ, Hoppe RT, et al. Long-term outcomes after high dose therapy and autologous haematopoietic cell rescue for refractory/relapsed Hodgkin lymphoma. Br J Haematol. 2012;159:329-39.

99. Ramsey SD, Nademanee A, Masszi T, Holowiecki J, Abidi M, Chen A, et al. Quality of life results from a phase 3 study of brentuximab vedotin consolidation following autologous haematopoietic stem cell transplant for persons with Hodgkin lymphoma. Br J Haematol. 2016;175:860-7.

\section{Publisher's Note}

Springer Nature remains neutral with regard to jurisdictional claims in published maps and institutional affiliations. 